Cite this: J. Mater. Chem. C, 2014, 2 , 3367

Received 2nd November 2013 Accepted 27th December 2013

DOI: $10.1039 / \mathrm{c} 3 \mathrm{tc} 32165 \mathrm{~g}$

www.rsc.org/MaterialsC

\title{
Novel design of organic donor-acceptor dyes without carboxylic acid anchoring groups for dye-sensitized solar cells $\dagger$
}

\begin{abstract}
Tsuyoshi Michinobu, ${ }^{\text {*a }}$ Norifusa Satoh, ${ }^{\text {tb }}$ Jinhua Cai, $\star^{\mathrm{b}}$ Yongrong Li ${ }^{\mathrm{a}}$ and Liyuan Han ${ }^{\mathrm{b}}$
Organic donor-acceptor dyes, formed by a high-yielding [2 + 2] cycloaddition-retroelectrocyclisation process between aniline-substituted alkynes and tetracyanoethylene (TCNE) or 7,7,8,8tetracyanoquinodimethane (TCNQ), were employed as novel photosensitizers without carboxylic acid anchoring groups in dye-sensitized solar cells (DSSCs). The efficient adsorption of the donor-acceptor dyes onto $\mathrm{TiO}_{2}$ was confirmed by UV-vis and IR spectroscopies. The photovoltaic performances of the DSSCs suggested that the triphenylamine derivatives 3 and 4 provide higher current densities $\left(J_{s c}\right)$ as compared to the corresponding dimethylaniline counter molecules 1 and 2 . This was mainly due to the excellent charge-separation efficiencies and lower charge-recombination rates of the triphenylamine moieties. It was also found that the devices sensitized by the TCNQ-adducted dyes 2 and 4 display open-circuit voltages $\left(V_{\text {oc }}\right)$ higher than those of the TCNE-adducted counter dyes 1 and 3 . All these results were reasonably explained by the $J-V$ curve fitting based on the equivalent-circuit model as well as the comparison between the absorption and incident-photon-to-current-conversion efficiency (IPCE) spectra.
\end{abstract}

\section{Introduction}

Dye-sensitized solar cells (DSSCs) have attracted increasing attention due to their significant advantages of low cost, ease of manufacturing, and flexibility as compared to conventional silicon solar cells. ${ }^{1-6}$ The main component of DSSCs is the photosensitizer, which absorbs sunlight and generates electric charges. The high-performance sensitizers reported so far are $\mathrm{Ru}$ complexes, which show the maximum power conversion efficiencies (PCEs) exceeding $11 \% .^{7-9}$ However, the development of metal-free organic sensitizers has been ongoing because their physical properties, such as molar extinction coefficients and absorption ranges, can be controlled by their molecular design. The chemical structures of most efficient organic sensitizers consist of donor- $\pi$-acceptor systems bearing carboxylic acidbased anchoring groups at the acceptor site. ${ }^{10}$ The conventional

${ }^{a}$ Department of Organic and Polymeric Materials, Graduate School of Science and Engineering, Tokyo Institute of Technology, 2-12-1 Ookayama, Meguro-ku, Tokyo 152-8552, Japan. E-mail: michinobu.t.aa@m.titech.ac.jp; Fax: +81-3-5734-3774; Tel: +81-3-5734-3774

${ }^{b}$ Photovoltaic Materials Unit, National Institute for Materials Science, 1-2-1 Sengen, Tsukuba, Ibaraki 305-0047, Japan. E-mail: SATOH.Norifusa@nims.go.jp; Fax: +81298592301; Tel: +81-298592331

$\uparrow$ Electronic supplementary information (ESI) available: Optical and electrochemical data of 1-4 and IR spectra. See DOI: 10.1039/c3tc32165g

\$ Current address: Suzhou Institute of Nano-tech and Nano-Bionics, Chinese Academy of Science, no. 398 Ruoshui Road, SEID, Suzhou Industrial Park, Suzhou, Jiangsu Province, 215125, China. synthetic routes of the donor- $\pi$-acceptor moieties are based on metal-catalysed cross-coupling reactions, and the most common acceptor/anchoring group is cyanoacrylic acid. In other words, there is a limitation when designing new acceptor units. ${ }^{11-18}$

Recently, a more straightforward synthetic approach to donor- $\pi$-acceptor systems was introduced. It is based on the formal $[2+2]$ cycloaddition-retroelectrocyclisation reaction between activated alkynes and electron-poor alkenes. ${ }^{19-21}$ The alkyne activation is achieved by the substitution with electrondonating aromatic amines, allowing for the smooth progress of the reaction at room temperature in a click chemistry fashion. ${ }^{22-25}$ The common electron-poor alkenes in this reaction are tetracyanoethylene (TCNE) and 7,7,8,8-tetracyanoquinodimethane (TCNQ). The resulting TCNE-adducted structures are donor-substituted 1,1,4,4-tetracyanobuta-1,3-dienes (TCBDs), and the TCNQ-adducts are donor-substituted cyclohexa-2,5diene-1,4-diylidene-expanded TCBDs (Fig. 1). The important features of these chromophores include intramolecular chargetransfer interactions, potent redox activities, and nonplanar molecular arrangements. It is expected that the last feature contributes to the suppression of dye aggregation in the DSSCs. In addition, the chromophores do not possess any carboxylic acid groups. However, it was recently reported that dicyanomethylene-based compounds, such as TCNE and TCNQ, form surface complexes with $\mathrm{TiO}_{2} \cdot{ }^{26,27}$ This result suggests the possibility that polycyanated derivatives can efficiently adsorb onto $\mathrm{TiO}_{2}$. It is interesting to examine if this is also true for the 

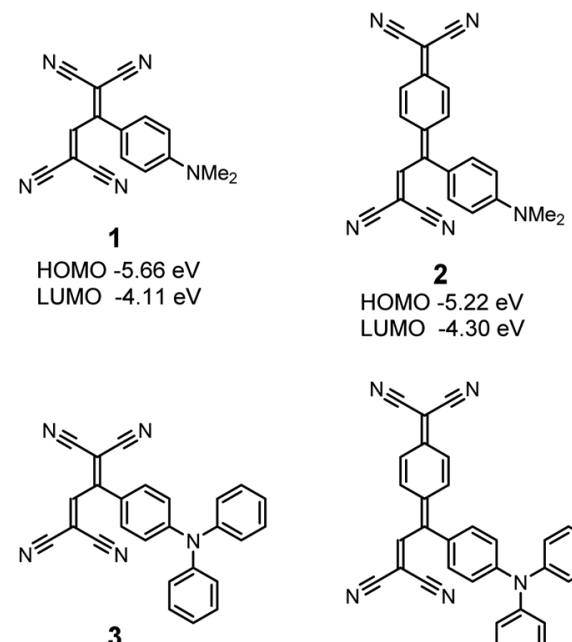

3

HOMO $-5.65 \mathrm{eV}$ LUMO $-4.18 \mathrm{eV}$

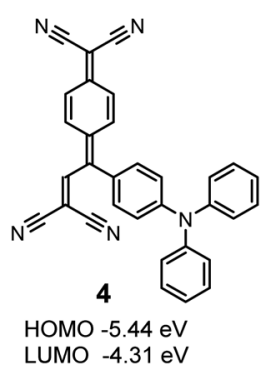

LUMO $-4.31 \mathrm{eV}$

Fig. 1 Chemical structures and energy levels of organic donoracceptor dyes 1-4.

tetracyanated donor-acceptor compounds. We now present a new design concept for organic sensitizers and report for the first time a detailed study of DSSCs based on donor-substituted TCBDs. Careful selection of both the donor and acceptor groups eventually led to the improvement of the photovoltaic performances.

\section{Experimental section}

\section{Materials}

All the reagents were purchased from Kanto, Tokyo Kasei, Wako, and Aldrich. 2-(4-(Dimethylamino)phenyl)buta-1,3-diene-1,1,4,4tetracarbonitrile (1), ${ }^{28}$ 2-(4-(3,3-dicyano-1-(4-(dimethylamino)phenyl)allylidene)cyclohexa-2,5-dien-1-ylidene)malononitrile (2), ${ }^{29}$ 2-(4-(diphenylamino)phenyl)buta-1,3-diene-1,1,4,4-tetracarbonitrile (3), ${ }^{30}$ and 2-(4-(3,3-dicyano-1-(4-(diphenylamino)phenyl)allylidene)-cyclohexa-2,5-dien-1-ylidene)malononitrile $(4)^{30}$ were synthesized according to the reported methods. Although the reaction yields were almost quantitative, 1-4 were carefully purified by column chromatography $\left(\mathrm{SiO}_{2}, \mathrm{CH}_{2} \mathrm{Cl}_{2}\right)$ in order to avoid any contaminations. The spectroscopic characterization data of 1-4 agreed with the reported data. In addition, the purity was confirmed by elemental analysis: 1 calcd (\%) for $\mathrm{C}_{16} \mathrm{H}_{11} \mathrm{~N}_{5}$ (273.30): C 70.32, $\mathrm{H} 4.06, \mathrm{~N} 25.63$; found: $\mathrm{C} 70.42, \mathrm{H}$ 4.41, $\mathrm{N} 25.21 ; 2$ calcd (\%) for $\mathrm{C}_{22} \mathrm{H}_{15} \mathrm{~N}_{5}$ (349.40): C 75.63, $\mathrm{H} 4.33$, $\mathrm{N} 20.04$; found: $\mathrm{C} 75.68, \mathrm{H} 4.83, \mathrm{~N} 19.49 ; 3$ calcd (\%) for $\mathrm{C}_{26} \mathrm{H}_{15} \mathrm{~N}_{5}$ (397.44): $\mathrm{C} 78.57, \mathrm{H} 3.80, \mathrm{~N} \mathrm{17.62}$; found: $\mathrm{C} 78.56, \mathrm{H}$ 4.33, $\mathrm{N} 17.11 ; 4$ calcd (\%) for $\mathrm{C}_{32} \mathrm{H}_{19} \mathrm{~N}_{5}$ (473.54): $\mathrm{C}$ 81.17, H 4.04, $\mathrm{N} 14.79$; found: C 79.30, H 4.14, N 16.56\%.

\section{Cell fabrication and characterization}

The DSSC devices were fabricated as follows. A main transparent layer $(15 \mu \mathrm{m})$ with titania particles (about $20 \mathrm{~nm}$ ) and a scattering layer $(10 \mu \mathrm{m})$ with titania particles (about $400 \mathrm{~nm}$ )

were screen-printed onto the fluorine-doped tin oxide (FTO)conducting glass substrate. The films were then sintered at $500{ }^{\circ} \mathrm{C}$ for $1 \mathrm{~h}$. The thicknesses of the films were measured by a Surfcorder ET 4000 (Kosaka Laboratory, Ltd). The films were treated with a $0.1 \mathrm{M}$ aqueous solution of $\mathrm{HCl}$ before examination. Coating of the titania films was carried out by immersion in a $3 \times 10^{-4} \mathrm{M}$ solution of the sensitizers in $\mathrm{CH}_{3} \mathrm{CN} / \mathrm{tBuOH}$ $(1: 1, \mathrm{v} / \mathrm{v})$ for $24 \mathrm{~h}$ under a nitrogen atmosphere. Deoxycholic acid (DCA, $20 \mathrm{mmol}$ ) was added to the solution of the dye as a coadsorbent. The dye-covered $\mathrm{TiO}_{2}$ electrode and the Pt counter electrode were assembled into a sandwich-type cell and sealed with a hot-melt gasket ( $60 \mu \mathrm{m}$ thickness) that was made of the ionomer Surlyn1702 (DuPont). Finally, the electrolyte, which consisted of $2 \mathrm{M} \mathrm{LiI}$ and $0.025 \mathrm{M} \mathrm{I}_{2}$ in $\mathrm{CH}_{3} \mathrm{CN}$, was injected into the cell and sealed with a cover glass. The current-voltage characteristics were measured using an Advantest R6243 current-voltage unit after a $10 \mathrm{~min}$ wait time in order to achieve thermal equilibrium under AM 1.5G simulated solar light of $100 \mathrm{~mW} \mathrm{~cm}^{-2}$, irradiated from a WACOM super solar simulator, with a $0.25 \mathrm{~cm}^{2}$ mask to define the cell area.

\section{Results and discussion}

\section{Molecular design}

Four different donor-acceptor dyes 1-4 were prepared by the formal $[2+2]$ cycloaddition-retroelectrocyclisation reaction (Fig. 1). As previously reported, all compounds were obtained in quantitative yields at room temperature. The chemical structures were confirmed by NMR, IR, and MS spectrometry, which were consistent with the reported data. The longest wavelength absorption maxima $\left(\lambda_{\max }\right)$ and redox potentials of 1-4 are summarized in Table S1. $\dagger$ Also, the highest occupied molecular orbital (HOMO) and lowest unoccupied molecular orbital (LUMO) levels were estimated from the first oxidation potentials $\left(E_{\mathrm{ox}, 1}\right)$ and the first reduction potentials $\left(E_{\mathrm{red}, 1}\right)$, respectively, under the assumption of $\mathrm{Fc} / \mathrm{Fc}^{+}=-4.80 \mathrm{eV}$, and the values are shown in Fig. 1. The HOMO levels of the four dyes are in the range from -5.66 to $-5.22 \mathrm{eV}$, which are sufficiently low as compared to the redox potential level of the iodide/triiodide electrolyte couple $(-4.9 \mathrm{eV})$. This fact indicates the facilitated dye regeneration. On the other hand, the LUMO levels $(-4.31$ to $-4.11 \mathrm{eV})$ are close to the conduction band of $\mathrm{TiO}_{2}(-4.3 \mathrm{eV})$, ensuring the formation of the surface complexes of the dyes and $\mathrm{TiO}_{2}{ }^{26,27}$ A comparison of the acceptor moieties suggests that the LUMO levels of the TCNQ-adducts 2 and $\mathbf{4}$ are lower than those of the corresponding TCNE-adducts 1 and 3, respectively. This result reflects the strong electron-accepting power of TCNQ as compared to TCNE. The HOMO levels of $\mathbf{1}$ and $\mathbf{3}$ are almost the same, while 4 with the triphenylamine moiety shows a HOMO level lower than 2 with the dimethylaniline moiety. The lower HOMO or smaller ionization potential is a superior feature of the triphenylamine to dialkylaniline derivatives. Many triphenylamine frameworks have indeed been employed as hole-transporting materials in organic electroluminescence devices as well as stabilized cationic radicals of redox-active polymers. ${ }^{31-34}$ 


\section{Dye adsorption onto $\mathrm{TiO}_{2}$}

Since 1-4 do not possess any carboxylic acid anchoring groups, the adsorption behaviour on the $\mathrm{TiO}_{2}$ surface was first examined. The $\mathrm{TiO}_{2}$ powder does not show any visible absorption, but it became colourful when immersed into the dye solutions in $\mathrm{CH}_{3} \mathrm{CN}$. It is known that both TCNE and TCNQ form surface complexes with $\mathrm{TiO}_{2}$, and this event newly produces a welldefined visible absorption ascribed to the charge-transfer from the $\mathrm{TiO}_{2}$ surface to TCNE or TCNQ. ${ }^{26,27}$ In contrast to these surface complexes, the donor-acceptor dyes 1-4 show visible absorption bands due to an intramolecular charge-transfer. Thus, the colours of $\mathrm{TiO}_{2}$ with organic dyes were similar to the original dye colours. However, the absorption bands became broadened and the end absorption bathochromically shifted when the dye adsorption onto $\mathrm{TiO}_{2}$ occurred (Fig. 2). The bathochromic shifts in the end absorption of the TCNQ-adducts were more significant than those of the corresponding TCNE-adducts, indicating the noticeable charge-transfer interactions due to the stronger electron-accepting characteristics. Moreover, 3 and 4 with the triphenylamine donor displayed a negligible bathochromic shift in $\lambda_{\max }$ as compared to the corresponding dimethylaniline analogues 1 and 2, respectively. This might be due to the suppressed dye aggregation in terms of the propeller structure of the triphenylamine moiety. In addition to the absorption spectra, peak broadening was also observed in the IR spectra. For example, the cyano vibrational peak of $\mathbf{1}$ detected at $2212 \mathrm{~cm}^{-1}$ broadens on $\mathrm{TiO}_{2}$ (Fig. S1 $\dagger$ ). In the case of the surface complexes of highly symmetric and rigid dyes like TCNX (X $=\mathrm{E}$ or Q) on $\mathrm{TiO}_{2}$, the cyano vibrational peaks simply split due to the formation of coordinated and uncoordinated cyano groups. ${ }^{26,27}$ However, since the attached dimethylaniline and triphenylamine moieties break the symmetry, the cyano groups close to and far from the attached moieties give slightly different vibrational peaks and serve as the anchoring positions to provide the different chemical environments. Furthermore, it is possible to rotate the chemical structures around the single bond. Therefore, the dyes on $\mathrm{TiO}_{2}$ produce multiple peaks overlapping each other, resulting in the observed broad peak in the IR spectra.

\section{Photovoltaic performances of DSSCs}

The chemically adsorbed dyes 1-4 on $\mathrm{TiO}_{2}$, as confirmed above, produce the photocurrent density-photovoltage $(J-V)$ curves in

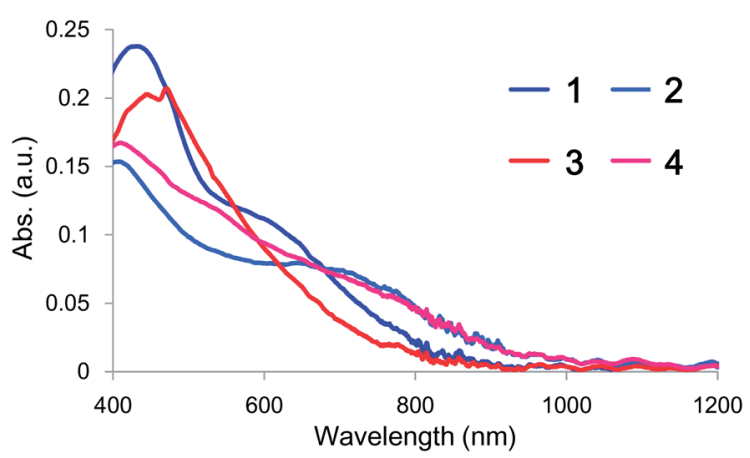

Fig. 2 Absorption spectra of organic dye ( $4 \mu \mathrm{m}$ thickness)-adsorbed $\mathrm{TiO}_{2}$ films. the DSSCs (Fig. 3). The detailed photovoltaic data are listed in Table 1 . The device sensitized by the triphenylaminesubstituted TCBD 3 exhibited a current density $\left(J_{\text {sc }}\right)$ of $0.65 \mathrm{~mA}$ $\mathrm{cm}^{-2}$, which is higher than that sensitized by the dimethylaniline-substituted TCBD $1\left(0.12 \mathrm{~mA} \mathrm{~cm}^{-2}\right)$. The TCNQ-adducts displayed a similar trend. The $J_{\mathrm{sc}}$ value of the device sensitized by the triphenylamine derivative 4 was $1.71 \mathrm{~mA} \mathrm{~cm}^{-2}$, while the device of the corresponding dimethylaniline analogue 2 displayed a $J_{\mathrm{sc}}$ of $1.41 \mathrm{~mA} \mathrm{~cm} \mathrm{~cm}^{-2}$. These results highlight the importance of the triphenylamine moiety as a donor unit. On the other hand, a comparison of the acceptor moieties clearly indicates the superiority of the TCNQ-adducts to the corresponding TCNE-adducts. In particular, the greater open-circuit voltages $\left(V_{\mathrm{oc}}\right)$ of the TCNQ-adducts originate from the elongated molecular sizes and suitable energy levels..$^{35,36}$ It is noteworthy that the $V_{\text {oc }}$ of the device sensitized by the TCNQ-adduct 2 is twice as high as that of the corresponding TCNE-adduct $\mathbf{1}$. Accordingly, the best photoconversion efficiency (PCE) of $0.25 \%$ was achieved for the device sensitized by the TCNQ-adduct 4 with the triphenylamine donor.

Fig. 4 shows the action spectra of incident photon-to-current conversion efficiency (IPCE) as a function of the incident wavelength for the DSSCs. In good agreement with the absorption spectra shown in Fig. 2, the IPCE action spectra of the devices sensitized by the TCNQ-adducts are broader than those of the TCNE-adducts. This is due to the extended absorption range of the TCNQ-adducts. It should be noted that the IPCE of the TCNQ-adducts covers the entire visible region. In addition, the overall IPCE values of the TCNQ-adducts are significantly higher than those of the TCNE-adducts. Although the light absorption amount is not so different on the photoelectrode (Fig. 2) and the HOMO levels of all the dyes are low

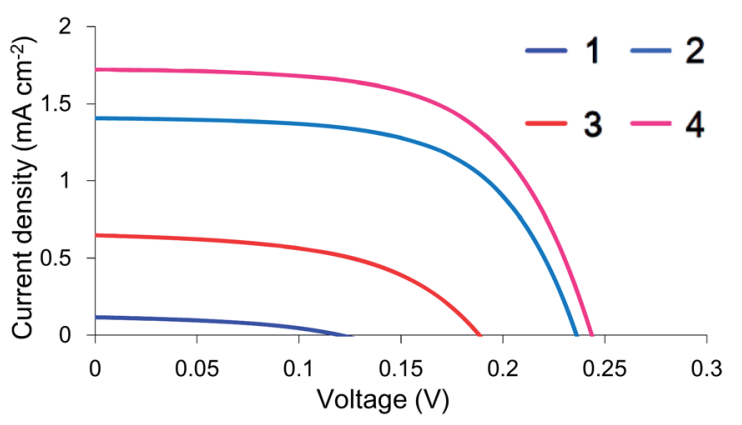

Fig. 3 Photocurrent density-photovoltage $(J-V)$ curves of DSSCs based on 1-4.

Table 1 Summary of DSSC performances ${ }^{a}$

\begin{tabular}{lllll}
\hline & $J_{\text {sc }}\left(\mathrm{mA} \mathrm{cm}^{-2}\right)$ & $V_{\text {oc }}(\mathrm{V})$ & FF & PCE $(\%)$ \\
\hline $\mathbf{1}$ & 0.12 & 0.12 & 0.42 & 0.0058 \\
2 & 1.41 & 0.24 & 0.61 & 0.20 \\
3 & 0.65 & 0.19 & 0.52 & 0.063 \\
$\mathbf{4}$ & 1.71 & 0.24 & 0.61 & 0.25
\end{tabular}

${ }^{a} 0.25 \mathrm{~cm}^{2} \mathrm{TiO}_{2}$ electrode composed of a transparent layer $(15 \mu \mathrm{m})$ and scattering layer $(10 \mu \mathrm{m})$ in $\mathrm{CH}_{3} \mathrm{CN}$ containing $2 \mathrm{M}$ LiI and $0.025 \mathrm{M} \mathrm{I}_{2}$. 


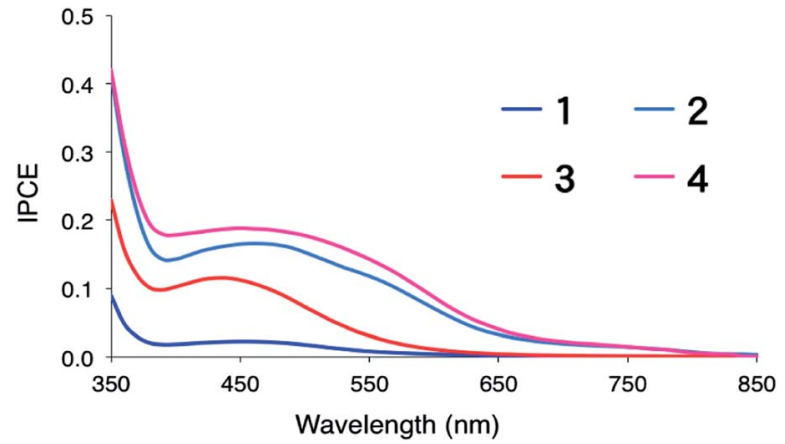

Fig. 4 IPCE spectra of DSSCs based on 1-4.

enough to accept electrons from the electrolyte, the TCNQadducts have more-expanded $\pi$ electrons on the HOMO orbitals based on a density functional calculation. ${ }^{26}$ The expanded $\pi$ orbitals would stabilize the oxidized states for the smooth electron relay to generate the photocurrent. Similarly, the triphenylamine moiety improves $J_{\mathrm{sc}}$ and IPCE due to the $\pi$-electron expansion on the HOMO orbitals and better redox properties. Note that reversible oxidation waves ascribed to the triphenylamine units of $\mathbf{3}$ and $\mathbf{4}$ are reported. ${ }^{30}$

\section{$I-V$ parameter analysis}

The $J-V$ curves of the DSSCs based on 1-4 were analysed using the theoretical equation based on the equivalent-circuit model (eqn (1)):

$$
I=I_{\mathrm{ph}}-I_{0}\left\{\exp \left[\frac{e\left(V+I R_{\mathrm{s}}\right)}{n k T}\right]-1\right\}-\frac{V+I R_{\mathrm{s}}}{R_{\mathrm{sh}}}
$$

where $I$ is the output electric current $(I=0.25 J), V$ is the output electric voltage, $e$ is the elementary charge, $k$ is Boltzmann's constant, $T$ is the absolute temperature, $I_{\mathrm{ph}}$ is the photocurrent,
$I_{0}$ is the reverse saturation current of the diode, $n$ is the ideality factor of the diode, $R_{\mathrm{S}}$ is the series resistance, and $R_{\mathrm{sh}}$ is the shunt resistance. ${ }^{37}$ By applying a fitting process to the $J-V$ curves, the $I^{-}$ $V$ parameters $\left(I_{\mathrm{ph}}, I_{0}, n, R_{\mathrm{s}}\right.$, and $\left.R_{\mathrm{sh}}\right)$ were obtained with a high accuracy. Assisted by some theoretical models or equations, e.g., Shockley equation for the $\mathrm{p}-\mathrm{n}$ junction, the $I-V$ parameters have been extensively used to analyse the physics in traditional semiconductor solar cells. Note that $J_{\mathrm{sc}}, V_{\mathrm{oc}}$, and FF are convenient to characterise the $J-V$ curve shapes and the PCE, but not appropriate to discuss the photovoltaic performances because the $I-V$ parameters have a complex influence on the value of $J_{\mathrm{sc}}$, $V_{\text {oc }}$, and FF. To better understand the photovoltaic performances, the $I-V$ parameter analysis is important in solar cell research. The validity of using the equivalent circuit to fit the $J-V$ curves of organic solar cells and DSSCs was recently reported. ${ }^{38-40}$

Fig. 5 summarizes the $I-V$ parameters obtained by fitting the $J-V$ curves of the DSSCs based on 1-4. The $I_{\mathrm{ph}}$ values increased when the dimethyaniline donor was replaced by the triphenylamine donor in both cases of the TCNE- $(\mathbf{1} \rightarrow \mathbf{2})$ and TCNQadducts $(3 \rightarrow 4)$ (Fig. 5(a)). This increase in the $I_{\mathrm{ph}}$ is due to the enhanced charge separation efficiencies at the interface between the dyes and $\mathrm{TiO}_{2}$ as already discussed. On the other hand, both of the diode parameter values, $I_{0}$ and $n$, of the devices sensitized by the triphenylamine-based dyes were lower than those sensitized by the dimethylaniline-based dyes (Fig. 5(b) and (d)). Generally, it is difficult to determine whether or not the concept of suppressing the recombination current from $\mathrm{TiO}_{2}$ to the electrolyte functions from the values of $V_{\text {oc }}$ because $V_{\text {oc }}$ simultaneously correlates with $I_{\mathrm{ph}}, I_{0}$, and $n$ as follows:

$$
V_{\mathrm{oc}}=\frac{n k T}{e}\left[\ln \left(\frac{I_{\mathrm{ph}}}{I_{0}}\right)+1\right]
$$

However, the decrease in $I_{0}$ clearly suggests that the triphenylamine moiety suppresses the amount of recombination
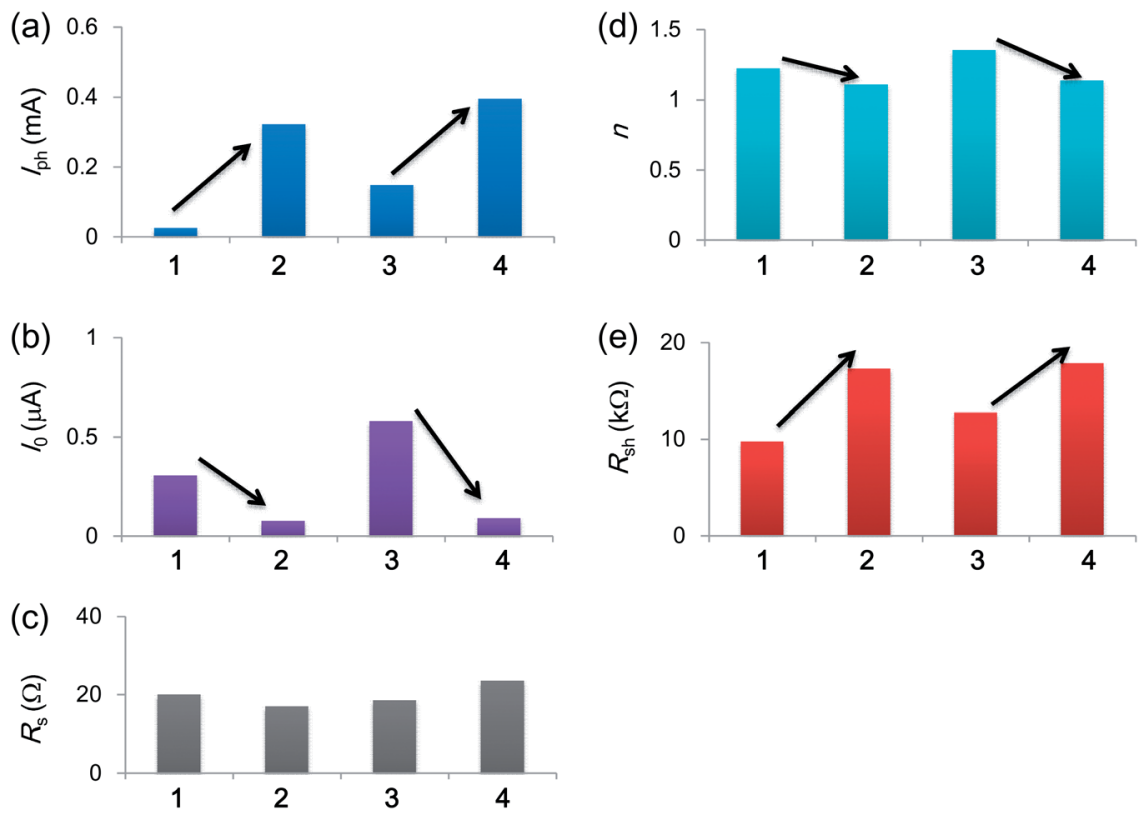

Fig. 5 Analysis results of the photocurrent density-photovoltage curves of DSSCs based on 1-4 using the equivalent-circuit model. 
current to improve $V_{\mathrm{oc}}$ as well as the enhanced $I_{\mathrm{ph}}$. The $R_{\mathrm{s}}$ values did not show any remarkable differences between the four devices, implying that the transparent electrode, counter electrode, and electrolyte solutions do not affect the photovoltaic parameters in the cell-assembling process (Fig. 5(c)). Although it is well known that the reduction of $R_{\mathrm{s}}$ improves $\mathrm{FF},{ }^{41}$ the triphenylamine moiety could realise the high FF without decreasing $R_{\mathrm{s}}$. This improvement is explained by the increase in $V_{\text {oc }}$ based on the theoretical background of an ideal solar cell with no $R_{\mathrm{S}}$ and no $R_{\mathrm{sh}}$; the relationship between $V_{\mathrm{oc}}$ and FF is given as follows: ${ }^{22}$

$$
\mathrm{FF} \approx 1-\frac{k T}{V_{\mathrm{oc}}}
$$

In contrast, a clear increase in the $R_{\mathrm{sh}}$ values occurred when the dimethylaniline donor was exchanged by the triphenylamine donor (Fig. 5(d)). This increase clearly reflects the decrease in the leak current, e.g., that from $\mathrm{TiO}_{2}$ to organic dyes. In short, the triphenylamine moiety regulates the current on the photovoltaic interface to enhance the photoinduced current and to suppress the recombination and leak currents. All these results again support the significant utility of the triphenylamine unit as a donor moiety of DSSC dyes even when using the new anchoring group. ${ }^{43-47}$

\section{Conclusions}

New types of organic donor-acceptor dyes for DSSCs were introduced. They can be synthesized by click chemistry reactions, enabling large scale production at a low cost. The tetracyanated acceptor moieties of the dyes were efficiently attached to the $\mathrm{TiO}_{2}$ surface without special treatments. In particular, the expanded tetracyanated acceptor, originating from TCNQ, showed better photovoltaic performances than the simple TCBD analogue. Moreover, it was demonstrated that the use of the triphenylamine donor offers significant advantages, such as enhanced charge separation efficiencies, a lower charge recombination, and suppressed dye aggregation. These are important design concepts of the donor and acceptor moieties. Further development of effective $\pi$-spacers that control the electronic communication between the donor and acceptor moieties will lead to high performance organic dyes.

\section{Acknowledgements}

This work is partially supported by a Grant-in-Aid for Scientific Research from MEXT, Japan (no. 22685023), the Konica Minolta Science and Technology Foundation, and the Murata Science Foundation (T. M.). We acknowledge R. Yoshida (NIMS) for his technical assistance and S. Genseki (Center for Advanced Materials Analysis, Tokyo Institute of Technology) for the elemental analyses.

\section{Notes and references}

1 A. Hagfeldt, G. Boschloo, L. Sun, L. Kloo and H. Pettersson, Chem. Rev., 2010, 110, 6595-6663.
2 A. Listorti, B. O'Regan and J. R. Durrant, Chem. Mater., 2011, 23, 3381-3399.

3 M. Grätzel, R. A. J. Janssen, D. B. Mitzi and E. H. Sargent, Nature, 2012, 488, 304-312.

4 B. E. Hardin, H. J. Snaith and M. D. McGehee, Nat. Photonics, 2012, 6, 162-169.

5 C. Qin, W.-Y. Wong and L. Han, Chem. - Asian J., 2013, 8, 1706-1719.

6 S. Zhang, Y. Xudong, Y. Numata and L. Han, Energy Environ. Sci., 2013, 16, 1443-1464.

7 A. Yella, H.-W. Lee, H. N. Tsao, C. Yi, A. K. Chandiran, M. K. Nazeeruddin, E. W.-G. Diau, C.-Y. Yeh, S. M. Zakeeruddin and M. Grätzel, Science, 2011, 334, 629-634.

8 T. Kinoshita, J. T. Dy, S. Uchida, T. Kubo and H. Segawa, Nat. Photonics, 2012, 7, 535-539.

9 L. Han, A. Islam, H. Chen, C. Malapaka, B. Chiranjeevi, S. Zhang, X. Yang and M. Yanagida, Energy Environ. Sci., 2012, 5, 6057-6060.

$10 \mathrm{~J} . \quad$ N. Clifford, E. Martínez-Ferrero, A. Viterisi and E. Palomares, Chem. Soc. Rev., 2011, 40, 1635-1646.

11 Y. Ooyama, S. Inoue, T. Nagano, K. Kushimoto, J. Ohshita, I. Imae, K. Komaguchi and Y. Harima, Angew. Chem., Int. Ed., 2011, 50, 7429-7433.

12 Y. Ooyama, T. Nagano, S. Inoue, I. Imae, K. Komaguchi, J. Ohshita and Y. Harima, Chem. - Eur. J., 2011, 17, 14837-14843.

13 M. Katono, T. Bessho, S. Meng, R. Humphry-Baker, G. Rothenberger, S. M. Zakeeruddin, E. Kaxiras and M. Grätzel, Langmuir, 2011, 27, 14248-14252.

14 J. Mao, N. He, Z. Ning, Q. Zhang, F. Guo, L. Chen, W. Wu, J. Hua and H. Tian, Angew. Chem., Int. Ed., 2012, 51, 98739876.

15 L. Macor, M. Gervaldo, F. Fungo, L. Otero, T. Dittrich, C.-Y. Lin, L.-C. Chi, F.-C. Fang, S.-W. Lii, K.-T. Wong, C.-H. Tsai and C.-C. Wu, RSC Adv., 2012, 2, 4869-4878.

16 J. Zhao, X. Yang, M. Cheng, S. Li and L. Sun, ACS Appl. Mater. Interfaces, 2013, 5, 5227-5231.

17 Y. Ooyama, N. Yamaguchi, I. Imae, K. Komaguchi, J. Ohshita and Y. Harima, Chem. Commun., 2013, 49, 2548-2550.

18 Y. Ooyama, Y. Hagiwara, T. Mizumo, Y. Harima and J. Ohshita, New J. Chem., 2013, 37, 2479-2485.

19 M. Kivala and F. Diederich, Acc. Chem. Res., 2009, 42, 235248.

20 S.-i. Kato and F. Diederich, Chem. Commun., 2010, 46, 19942006.

21 T. Michinobu, Chem. Soc. Rev., 2011, 40, 2306-2316.

22 T. Michinobu, C. Boudon, J.-P. Gisselbrecht, P. Seiler, B. Frank, N. N. P. Moonen, M. Gross and F. Diederich, Chem. - Eur. J., 2006, 12, 1889-1905.

23 M. Morimoto, K. Murata and T. Michinobu, Chem. Commun., 2011, 47, 9819-9821.

24 Y.-L. Wu, M. C. Stuparu, C. Boudon, J.-P. Gisselbrecht, W. B. Schweizer, K. K. Baldridge, J. S. Siegel and F. Diederich, J. Org. Chem., 2012, 77, 11014-11026.

25 M. Stefko, M. D. Tzirakis, B. Breiten, M.-O. Ebert, O. Dumele, W. B. Schweizer, J.-P. Gisselbrecht, C. Boudon, M. T. Beels, I. Biaggio and F. Diederich, Chem. - Eur. J., 2013, 19, 12693-12704. 
26 R. Jono, J.-i. Fujisawa, H. Segawa and K. Yamashita, J. Phys. Chem. Lett., 2011, 2, 1167-1170.

27 S. Manzhos, R. Jono, K. Yamashita, J.-i. Fujisawa, M. Nagata and H. Segawa, J. Phys. Chem. C, 2011, 115, 21487-21493.

28 T. Michinobu, J. C. May, J. H. Lim, C. Boudon, J.-P. Gisselbrecht, P. Seiler, M. Gross, I. Biaggio and F. Diederich, Chem. Commun., 2005, 737-739.

29 M. Kivala, C. Boudon, J.-P. Gisselbrecht, P. Seiler and F. Diederich, Chem. Commun., 2007, 4731-4733.

30 X. Tang, W. Liu, J. Wu, C.-S. Lee, J. You and P. Wang, J. Org. Chem., 2010, 75, 7273-7278.

31 Y. Shirota and H. Kageyama, Chem. Rev., 2007, 107, 9531010.

32 T. Michinobu, H. Kumazawa, E. Otsuki, H. Usui and K. Shigehara, J. Polym. Sci., Part A: Polym. Chem., 2009, 47, 3880-3891.

33 H.-J. Yen and G.-S. Liou, Polym. Chem., 2012, 3, 255-264.

34 Y. Li and T. Michinobu, J. Polym. Sci., Part A: Polym. Chem., 2012, 50, 2111-2120.

35 A. Reynal, A. Forneli, E. Martinez-Ferrero, A. Sánchez-Díaz, A. Vidal-Ferran, B. C. O'Regan and E. Palomares, J. Am. Chem. Soc., 2008, 130, 13558-13567.

36 M. Miyashita, K. Sunahara, T. Nishikawa, Y. Uemura, N. Koumura, K. Hara, A. Mori, T. Abe, E. Suzuki and S. Mori, J. Am. Chem. Soc., 2008, 130, 17874-17881.
37 J. H. Cai, N. Satoh, M. Yanagida and L. Y. Han, J. Nonlinear Opt. Phys. Mater., 2010, 19, 637-643.

38 J. Cai, N. Satoh, M. Yanagida and L. Han, Rev. Sci. Instrum., 2009, 80, 115111.

39 J. Cai, N. Satoh and L. Han, J. Phys. Chem. C, 2011, 115, 60336039.

40 N. Satoh and L. Han, Phys. Chem. Chem. Phys., 2012, 14, 16014-16022.

41 L. Han, N. Koide, Y. Chiba, A. Islam, R. Komiya, N. Fuke, A. Fukui and R. Yamanaka, Appl. Phys. Lett., 2005, 86, 213501.

42 P. Würfel, in Physics of Solar Cells: From Basic Principles to Advanced Concepts, Wiley-VCH, Weinheim, 2007, pp. 155175.

43 U. Bach, D. Lupo, P. Comte, J. E. Moser, F. Weissörtel, J. Salbeck, H. Spreitzer and M. Grätzel, Nature, 1998, 395, 583-585.

44 N. Hirata, J.-J. Lagref, E. J. Palomares, J. R. Durrant, M. K. Nazeeruddin, M. Gratzel and D. D. Censo, Chem. Eur. J., 2004, 10, 595-602.

45 N. Satoh, T. Nakashima and K. Yamamoto, J. Am. Chem. Soc., 2005, 127, 13030-13038.

46 H. J. Snaith, S. M. Zakeeruddin, Q. Wang, P. Péchy and M. Grätzel, Nano Lett., 2006, 6, 2000-2003.

47 M. Liang and J. Chen, Chem. Soc. Rev., 2013, 42, 3453-3488. 